\title{
AS CONCEPÇÕES DE ACADÊMICOS SOBRE PRÁTICAS LÚDICAS EM UM PROJETO DE EXTENSÃO EM HEMOCENTRO
}

\author{
THE STUDENTS' CONCEPCIONS \\ ABOUT USING LUDIC PRACTICES \\ IN A BLOOD CENTER THROUGH \\ AN OUTREACH PROJECT
}

\author{
Ercília Maria Angeli Teixeira de Paula* \\ Monique de Oliveira da Silva** \\ Lucas Tagliari da Silva** \\ Marcos Antonio dos Santos ${ }^{* * * *}$
}

\section{RESUMO}

Este estudo tem como objetivo apresentar as concepções de acadêmicos do curso de Pedagogia e de Educação Física sobre os desafios e as reflexões de um Projeto de Extensão que é desenvolvido em um Hemocentro do interior do Paraná, envolvendo pessoas que possuem diferentes patologias sanguíneas, como Hemofilia, Talassemia, Anemia Falciforme, entre outras. A metodologia utilizada foi a análise de questionários que foram respondidos por sete participantes do referido projeto, contendo perguntas subjetivas sobre as suas perspectivas e compreensões a respeito da sua atuação nesse trabalho de extensão. Como resultado, foi possível identificar que os membros do Projeto têm dado um novo sentido às suas práticas e estão superando as indagações e impressões iniciais sobre os pacientes. Os princípios teóricos da Educação Social contribuem para o trabalho com os atendidos no Hemocentro no sentido de levar à compreensão da necessidade dos cuidados com a saúde e da luta pela garantia dos seus direitos. 0 Projeto possibilita que os pacientes interajam entre si e construam soluções coletivas para seus problemas e também se divirtam com as atividades e brincadeiras desenvolvidas. Outrossim, o trabalho desenvolvido também apresenta contribuições significativas para o processo de formação profissional, bem como para os aspectos sociais e principalmente humanos dos integrantes que compõem o grupo.

Palavras-chave: Formação de Professores; Práticas Lúdicas; Hemocentro.

\section{ABSTRACT}

This study aims to report the challenges and the reflections of students of Pedagogy and Physical Education about an outreach project carried out in Paraná. The project is developed in a blood center with people

\footnotetext{
* Professora da Universidade Estadual de Maringá (UEM), PR - Brasil. E-mail: erciliaangeli@yahoo.com.br

** Pedagoga. Universidade Estadual de Maringá (UEM), PR - Brasil. E-mail: moniqueoliveira.pedagogia@gmail.com

*** Aluno de Mestrado da Universidade Estadual de Maringá (UEM), PR - Brasil. E-mail: lu.cas.ts@hotmail.com

**** Aluno de Mestrado da Universidade Estadual de Maringá (UEM), PR - Brasil. E-mail: santosffe@gmail.com
} 
who have different blood disorders, such as Hemophilia, Thalassemia, Sickle Cell Anemia, among others. The methodology used was the analysis of questionnaires answered by seven participants of that project, with subjective questions about their perspectives and insights about their performance. As a result, it was possible to conclude that the outreach project gives a new impetus to the practice of its participants, allowing them to cope with queries and their initial impressions about patients. The theoretical principles of social education contribute to deal with patients so that they understand the importance of health care as well as the struggle to guarantee their rights. The project allows patients to interact with each other and build collective solutions to their problems as well as having fun with the activities and games. It also contributes significantly to the training process and to the human and social aspects of the group members.

Keywords: Teacher Training; Ludic Practices; Blood Center.

\section{Introdução}

As práticas lúdicas e educativas desenvolvidas por estudantes universitários dos cursos de Pedagogia e de Educação Física em Hemocentros no Brasil são recentes e ainda pouco conhecidas. Na formação inicial desses cursos, a educação "fora da escola" é discutida de modo secundário em disciplinas isoladas e/ou em Projetos de Extensão.

Pensando nisso, este trabalho tem como objetivo apresentar as concepçóes de acadêmicos do curso de Pedagogia e Educaçáo Física sobre os desafios e as reflexóes de um Projeto de Extensão ${ }^{1}$ desenvolvido em um Hemocentro do interior do Paraná, o qual teve como proposta fundamental refletir sobre as realidades e especificidades das crianças, adolescentes, jovens e adultos que fazem tratamento no Hemocentro e também propor diferentes açóes para a garantia dos direitos humanos nas áreas de educação e saúde. A origem do trabalho extensionista está vinculada à solicitação de profissionais da área da saúde do Hemocentro Regional de uma cidade do interior do Paraná, os quais observaram que muitos pacientes eram provenientes de outras cidades e viajavam para receber atendimento multidisciplinar, que era marcado para ser realizado durante um único dia com intuito de facilitar a ida das pessoas ao Hemocentro.

Dessa maneira, apesar do atendimento ser concentrado para oportunizar poucas viagens, os pacientes esperavam horas para serem atendidos e alguns precisavam realizar transfusão de sangue que, às vezes, demorava de quatro a seis horas. Sendo assim, os profissionais do Hemocentro, preocupados com o longo período de espera do atendimento, solicitaram aos docentes do curso de Pedagogia a oferta de atividades lúdicas e educativas nesse período para que as pessoas se sentissem acolhidas e apresentem uma melhor adesão ao tratamento.

Dessa maneira, uma docente do curso de Pedagogia de uma universidade pública do interior do Paraná, acadêmicos dos cursos de graduação em Educação Física e Pedagogia, estudantes do Programa de Pós-Graduação em Educação e uma pedagoga egressa da universidade se uniram em agosto de 2015 e, após várias visitas ao Hemocentro e diversas reunióes de planejamento e de formação, iniciaram as atividades do Projeto de Extensão em setembro do mesmo ano.

De acordo com Oliveira (2010), para os diferentes profissionais que atuam em Hemocentros, a preparação dos estudantes e profissionais que irão trabalhar nesse contexto consiste em estudos, discussóes e pesquisas relacionadas às doenças ocasionadas no sangue, mais conhecidas pela terminologia científica como doenças Hematopatológicas. 
A partir das discussóes sobre as patologias e também do esclarecimento dos profissionais do Hemocentro a respeito de como atuar com pacientes Hemofílicos, com Anemia Falciforme, Talassemia e outras doenças do sangue, foram realizadas práticas lúdicas e educativas. Através do contato com os pacientes e seus familiares, todos têm a oportunidade de conhecer as realidades dos pacientes, suas vidas, seus contextos culturais, econômicos e sociais. Também foi possível identificar as brincadeiras, músicas e histórias prediletas dos pacientes e propor novas atividades em conjunto.

Ao longo do desenvolvimento do Projeto percebeu-se que a acolhida dos pacientes foi um momento significativo para o estabelecimento de vínculos que proporcionam as criaçōes lúdicas. Sendo assim, as brincadeiras são construídas de maneira coletiva. A roda de conversa inicial permite saber quem são as crianças, adolescentes e/ou adultos, quais as cidades residem, quais suas patologias, suas maiores fragilidades que evidenciam, suas coagulopatias, entre outros aspectos pessoais. Essas são algumas informaçôes iniciais dentre tantas outras que, a partir de uma boa receptividade, podem ser um diferencial das práticas e para repensar a teoria.

Nas rodas de conversa iniciais estão expressos os princípios teóricos metodológicos da Educaçáo Social em Saúde, que se fundamenta na prática da Educação Popular na qual os indivíduos problematizam em conjunto suas dificuldades, angústias e constróem soluçôes coletivas para seus problemas. Também são destacados os trabalhos com a emancipação social das pessoas envolvidas nessas intervençôes. Segundo Paula (2014),

a visão de mundo que reforça o valor do sonho e da utopia numa perspectiva da história como possibilidade é coerente com os princípios da Educação Popular como caminho para a emancipaçáo dos oprimidos. Isso representa considerar o ser humano como um ser histórico e social.

É preciso destacar que o trabalho com crianças envolve o lúdico como um elemento agregador e desencadeador para as discussóes das realidades vividas. O Projeto de Extensão se dedica a desenvolver açôes sociais, lúdicas e educacionais construídas de forma coletiva com as classes populares na busca de construçôes teóricas e práticas da Educação Social no Brasil, a qual procura atuar com essas pessoas para o enfrentamento das injustiças e desigualdades sociais na busca da promoção do empoderamento, mais especificamente do protagonismo infanto-juvenil.

Para Natali (2016, p. 18), a "Educaçáo Social trata da potencialização dos sujeitos em direção às construçôes culturais da sua época”. Dessa maneira, é preciso buscar açôes que superem os dilemas contemporâneos impostos pelos governos excludentes, além de lutar constantemente pela garantia dos direitos e por melhores condiçóes de vida para todas as pessoas.

Segundo Müller et al. (2010), a Educação Social precisa estimular o sujeito no tempo presente para que seja instrumentalizado a fim de enfrentar os desafios da sua vida e modificar o seu contexto, a partir da leitura da sua realidade e do seu passado. No caso do Hemocentro, a Educação Social atua desde a promoção de atividades lúdicas da cultura da infância até de discussão sobre a manutenção de direitos mais amplos, como a garantia do atendimento de qualidade pelo Sistema Único de Saúde (SUS).

Outra discussão referente à Educaçáo Social está voltada para as análises dos indicadores de avaliação para essas práticas educativas e lúdicas, os quais, de acordo com Souza (2016), precisam ser diferenciados das práticas educativas formais das escolas, pois apresentam características diferentes na forma de estruturação e operacionalização. Ainda 
para Souza (2016, p. 18), as intervençóes realizadas nos projetos de Educação Social são amplas, pois "A educação ultrapassa os muros da escola, não só porque se diferencia em relação ao conteúdo que transmite, mas também porque não só é ali que está o acesso ao conhecimento. A educação ocorre em diferentes espaços”. Dessa maneira, faz-se necessário pensar em estratégias para realizar o trabalho e poder avaliá-lo também nas suas características próprias.

Aliados a essas discussões, os referenciais teóricos da Educação em Saúde de Gazzinelli e colaboradores (2005) também estão presentes no Projeto de Extensão. Para os autores, não é possível pensar na Educação em Saúde em uma perspectiva determinista e linear, pois nesse trabalho

Ressalta-se a formaçáo de uma rede de solidariedade entre educadores e educandos, na qual busca-se o compartilhamento e o desenvolvimento de potencialidades na tentativa de ultrapassar limites e dificuldades, outorgando autonomia dos sujeitos envolvidos. (GAZZINELLI et. al., 2005, p. 204).

As práticas realizadas no Projeto de Extensão aqui relatado são regidas por esses princípios e por açóes educativas que envolvem o respeito, o compromisso, a inclusáo, a participação, o diálogo e a garantia dos direitos das crianças e dos adolescentes. É preciso destacar que o conhecimento das patologias e suas características também é um aspecto importante para a realização do Projeto de Extensão e elaboração das açóes. Para tanto, os estudantes têm a necessidade de pesquisar informaçóes sobre como é trabalhar com pessoas que apresentam diferentes limites que a própria doença impóe aos seus organismos.

Paula e Foltran (2007) enfatizam que quando uma criança ou adolescente no curso de seu desenvolvimento se descobre portador de uma patologia, a sua forma de ver o mundo tem continuidade, mas muitas vezes acontece uma série de alteraçóes na própria rotina e também na sua família. As autoras constataram que o brincar é essencial para a saúde física, emocional e intelectual do ser humano, em qualquer idade, para promoção e incentivo ao desenvolvimento.

Quando as pessoas brincam, elas desenvolvem o equilíbrio e reciclam suas emoçóes vividas, além de motivar outros elementos como a atenção, a concentração e muitas outras habilidades, uma vez que mergulham em um mundo de possibilidades. Assim, esse é um momento de recriar e enfrentar situaçóes por elas vividas no dia a dia, por isso o brincar para pessoas em tratamento de saúde náo pode ser vazio, precisa ser planejado e por vezes repensado para que a saúde física e emocional dessas pessoas seja preservada. A seguir será descrita a forma como o Projeto de Extensão foi realizado.

\section{Planejamento para as intervençóes do projeto}

O Projeto de Extensáo iniciou suas intervençóes em agosto de 2015 na universidade e foram realizados encontros com a coordenadora do Projeto e os estudantes para discussão, conhecimento e esclarecimento das patologias que o Hemocentro atende. A partir disso, foram construídos diferentes modelos de planejamentos para a realização das açôes a serem desenvolvidas ao longo do ano. Esses encontros foram necessários antes de iniciar as práticas educativas e lúdicas no Hemocentro 
Semanalmente aconteceram duas intervençóes dos estudantes com as pessoas em tratamento de saúde que frequentam o Hemocentro (segundas e quartas-feiras) e também aconteceram encontros quinzenais da equipe (quintas-feiras) para a realização de planejamentos e avaliaçóes das práticas. As intervençóes realizadas no Hemocentro são lúdicas e educativas e o objetivo é sempre proporcionar momentos de aprendizado e muita alegria, não somente para os pacientes, mas também para os familiares que os acompanham nas consultas, uma vez que a principal finalidade da proposta educativa é ajudá-los no enfrentamento dos processos de tratamento das doenças e de compreensáo das suas potencialidades e limitações.

Para compreender as patologias são realizadas pesquisas constantes. De acordo com a Federação Brasileira de Hemofilia (2015), a Hemofilia é um distúrbio genético que afeta os fatores de coagulação sanguínea. A respeito da Talassemia, a Associação Brasileira de Talassemia - ABRASTA (2016) a define como uma desordem hereditária que é transmitida por meio do pai ou da mãe para seus filhos; comumente produz anemia, ou seja, é uma falha genética que leva a uma malformação da Hemoglobina. Quanto à Anemia Falciforme, é uma hemoglobinopatia hereditária, ou seja, não é contagiosa e é mais frequente na população negra por ter sido originado no continente africano. Essa doença ocorre devido a uma alteração genética fazendo com que as hemácias, ao invés de forma arredondada, possuam um formato de foice que acaba destruindo as demais hemácias, por isso a necessidade de transfusão de sangue quinzenalmente.

Todas essas patologias apresentam algumas limitaçôes físicas para os pacientes. No caso da Hemofilia, eles têm dificuldades de coagulação do sangue, principalmente aqueles acometidos pela Hemofilia grave, pois qualquer movimento exagerado do organismo pode ocasionar hemorragias de difícil contenção. Atualmente, o tratamento profilático com a aplicaçáo de medicamentos; essas hemorragias são contidas, entretanto, é preciso tomar muito cuidado para que os hemofílicos não se machuquem. Em relação à Talassemia e à Anemia Falciforme, elas podem ocasionar problemas no fígado, baço, fazendo pés e mãos incharem, o que dificulta exercícios físicos. É preciso cuidado redobrado com essas pessoas.

Braga (2007, p. 234) apresenta um conceito sobre a importância do exercício físico para pacientes que fazem tratamento de saúde em Hemocentros:

A prática de exercícios pode ser encorajada, desde que as atividades sejam regulares, moderadas e o esforço progrida lentamente. O próprio paciente deve monitorar a medida adequada para ele quanto ao esforço físico. Os responsáveis e o paciente devem ser alertados sobre a necessidade da hidratação, antes, durante e após as atividades físicas.

Portanto, no Projeto de Extensão, todas as atividades são pensadas antecipadamente de forma responsável para que não coloquem em risco a integridade física das pessoas em tratamento de saúde. Por vezes, aparentemente os pacientes não são necessariamente frágeis fisicamente, mas elas precisam de cuidados especiais. O conhecimento sobre o tratamento e procedimentos médicos que cada doença exige é adquirido por meio do grupo de estudos que ocorre uma vez por semana (sextas-feiras) e nos planejamentos, momentos nos quais são estudadas as patologias do sangue a partir de dissertaçóes, artigos acadêmicos, informaçôes adquiridas no Hemocentro e relatos dos pais e profissionais da saúde que atuam na instituição. 
Segundo Oliveira (2010), apesar de precisar de certos cuidados, as doenças do sangue não impedem que essas crianças e adolescentes tenham uma vida normal. É preciso que os educadores se interessem pelo desenvolvimento dessas pessoas, considerando que a educação e a ludicidade são inseparáveis nas açôes no Hemocentro, pois proporcionam momentos de alegrias e amenizaçôes da dor e sofrimento, tanto para os pacientes quanto para seus familiares.

A partir dessas informações, tem sido possível constatar que é preciso ter o máximo de cuidado na escolha das atividades para não provocar nenhum dano à integridade física dos pacientes. Assim, também se faz necessário o desenvolvimento de estudos e pesquisas para elaboraçáo de novas brincadeiras.

\section{Intervençóes no hemocentro com os pacientes}

As práticas educativas e lúdicas no Hemocentro ocorrem em três momentos e, como o Projeto está em andamento, essas práticas são constantemente avaliadas e reavaliadas. Primeiramente são realizadas atividades iniciais que normalmente tem o intuito de proporcionar uma aproximação com os pacientes que ainda não tiveram a possibilidade do contato com o Projeto de Extensáo. O objetivo dessa atividade é estabelecer laços que permitam conhecer melhor as características pessoais, familiares e sociais das pessoas envolvidas e possibilitem que elas discutam os motivos pelos quais fazem tratamento no Hemocentro.

A brincadeira inicial é com uma bolinha. Todos os integrantes do Projeto - crianças, adolescentes, familiares e estudantes - se reúnem em círculo e passam a bolinha uns para os outros dizendo os seus nomes; esse é um momento de apresentaçáo. Posteriormente, cada integrante precisa dizer o seu nome e dos colegas e, nessa roda inicial de conversa, também são feitas algumas conversas sobre o que os pacientes gostam de brincar, se estão na escola e de qual cidade são provenientes.

É preciso destacar que, seguidamente a essas brincadeiras, um estudante é responsável por uma entrevista mais sistematizada com os familiares e os pacientes. Nessa entrevista, pergunta-se sobre dados pessoais, escolarização, patologias, idade e cidade, um levantamento que auxilia na obtenção dos dados de caracterização das pessoas atendidas, no planejamento e acompanhamento, bem como no conhecimento das doenças hematológicas mais recorrentes dos pacientes que frequentam o Hemocentro. Essas informaçōes também contribuem para o relatório das açōes do Projeto.

No início das intervençóes, os estudantes solicitam aos pacientes e familiares a autorização das imagens através de consentimento informado aprovado pelo Comitê de ética do Hospital Universitário no qual o Hemocentro está relacionado.

No segundo momento, são realizadas atividades intermediárias que proporcionam o bem-estar, autonomia, criatividade, curiosidade, desenvolvimento da linguagem verbal e corporal, tais como: contaçáo de histórias, telefone sem fio, estátua, careca cabeludo, mímica, batata-quente, passa anel, quebra-cabeça com bexigas, caça ao tesouro, atividades artísticas, atividades musicais, jogos de tabuleiro, de adivinhação e raciocínio.

De acordo com Lieberman (1997) os jogos voltados para a promoção da saúde colaboraram para a obtenção de conhecimentos sobre prevenção e autocuidado. Essas 
atividades promovem a socialização entre as pessoas, entre os familiares e os participantes do Projeto, já que nas rodas de conversas intercaladas nas brincadeiras os estudantes têm a oportunidade de conhecer as histórias de vidas, os desejos e as dificuldades de conviver com essas doenças; eles também aprendem e desenvolvem uma consciência crítica a respeito dos direitos e da condição de vida das pessoas que realizam tratamento de saúde no Hemocentro.

Para finalizar as intervençóes, em um terceiro momento, são realizadas atividades artesanais e/ou de literatura infantil. Pelo fato dessas atividades exigirem maior concentração de todos os envolvidos, essas práticas permitem uma aproximação maior com os pacientes, familiares das crianças e adolescentes e com os colaboradores do trabalho de extensão.

Vygotsky (1991) afirma que o lúdico tem influência no desenvolvimento da criança e que os benefícios do ato de jogar são: aprender a tomar algumas decisóes; estimular a curiosidade; aumentar o poder de iniciativa e autoconfiança; desenvolver a linguagem verbal e corporal; e aumentar o poder de concentração. $\mathrm{O}$ jogo pode ser considerado uma poderosa ferramenta pedagógica, por isso o Projeto vem atuando com o desenvolvimento de jogos e brincadeiras que trabalham a percepção cognitiva, afetiva e social das crianças, adolescentes e familiares que acompanham seus filhos.

A metodologia do Projeto também é fundamentada na Educação Social, por esse motivo são elaboradas rodas de estudos e conversas, produçấo de relatórios, registros em diário de campo com relatos e fotografias e avaliaçōes constantes das intervençōes pelo grupo e pelos próprios pacientes e familiares, os quais também sugerem novas atividades e brincadeiras.

Com brincadeiras coletivas sistematizadas, as crianças desenvolvem a socializaçáo, coordenação motora e cognição. Vale salientar que direcionados pela Educação Social no Hemocentro também é possível encontrar um espaço de exercício da cidadania e conscientizaçáo política dos direitos e deveres da criança e do adolescente, considerando a importância do lúdico em suas vidas. Muitas atividades são baseadas no Estatuto da Criança e do Adolescente - ECA (BRASIL, 1990) com intuito das pessoas conhecerem seus direitos, principalmente em relação à saúde, educação e desenvolvimento humano, no qual o lúdico tem importante atuação.

\section{Metodologia - aplicaçáo dos questionários sobre as concepçóes dos acadêmicos a respeito projeto de extensáo}

Para fundamentar este trabalho, foram utilizadas três produçôes acadêmicas, começando por um artigo que discute Projetos de Extensão com crianças e adolescentes, além de açôes de acadêmicos em uma brinquedoteca hospitalar - "Projeto brilhar: Brinquedoteca, literatura e arte no ambiente hospitalar", de Paula e Foltran (2007). Também foi considerada a dissertação "Brincar(es) na Infância: Possibilidades no Contexto da Doença Falciforme e da Hemofilia" de Oliveira (2010), estudo que apresenta açóes de acadêmicos em um Hemocentro.

Outro artigo que serviu de referência para as ações dos profissionais de Educação Física no trabalho com pessoas em tratamento de saúde foi a pesquisa de Invernizzi e Vaz 
(2016) sobre "Tempo e conhecimento na Educação Física dos primeiros anos do ensino fundamental em classe hospitalar: algumas questōes". Nesse artigo, os autores discutem práticas educativas de estagiários de Educação Física em Classe Hospitalar em Santa Catarina e analisam as açóes dos estagiários com as crianças e adolescentes.

Todas essas produçôes auxiliaram na elaboração dos questionários e análises de concepçóes dos Projetos de Extensão que se desenvolvem em Brinquedotecas Hospitalares, Classes Hospitalares e Hemocentros. Com essa base, foram aplicados sete questionários para os integrantes do Projeto sendo: duas estudantes de Pedagogia, uma estudante de Educação Física, três pós-graduandos de Educação e uma estudante egressa do Curso de Pedagogia. Os nomes desses colaboradores foram alterados para as identidades serem preservadas e, assim, suas respostas foram identificadas com sílabas e consoantes. Os estudantes assinaram um Consentimento Informado autorizando a pesquisa.

Em relação às características do questionário, a primeira pergunta feita aos participantes do Projeto no Hemocentro foi sobre o interesse de participar do Projeto de Extensão na Universidade. Em geral, os entrevistados responderam que esse trabalho é a oportunidade de conhecer e aprender sobre a Pedagogia Hospitalar, Educação Social e não somente compreender essas áreas na teoria, mas também na prática. Eles salientaram que a contribuição do Projeto não é apenas para a formação dos participantes, mas também para o bem-estar da comunidade em tratamento de saúde.

Os questionários apresentavam as seguintes questôes para os estudantes: Qual o seu interesse de participar de um Projeto de Extensão na Universidade? Como ficou sabendo do Projeto e qual sua reação inicial? Como você pensava que era o Projeto no Hemocentro? Como você pensava que eram as crianças e adolescentes no Hemocentro? Sua percepção modificou após a realização do Projeto? Quais as atividades que você mais gosta de realizar no Projeto e o momento que mais lhe marcou? Qual a contribuição do Projeto para a sua formaçáa?

Todos os participantes tiveram conhecimento do Projeto de Extensão por meio da professora coordenadora que divulgou na universidade as açôes extensionistas. O projeto foi divulgado em cartazes distribuídos pelo campus, nas redes sociais e também foram realizados convites e apresentação do projeto nas salas de aula dos Cursos de Pedagogia e Educaçáo Física. Esses cursos foram escolhidos, pois a proposta é integrar atividades educacionais e lúdicas.

Os acadêmicos interessados passaram por uma seleção e entrevista para se saber suas preocupaçôes e interesses. As análises das respostas dos questionários que serão apresentadas a seguir estiveram fundamentadas na perspectiva teórica de Analise de Conteúdo de Bardin (2009) e as respostas dos estudantes foram decodificadas em categorias.

Em um primeiro momento, foi realizada uma pré-análise das respostas, posteriormente o material foi explorado e analisado em suas semelhanças e diferenças. Após esse tratamento metodológico, foram realizadas as inferências e interpretaçôes.

\section{Resultados das analises dos questionarios dos estudantes}

Em relação às análises dos questionários, quando os estudantes foram questionados sobre a reaçáo inicial ao tomarem conhecimento do Projeto ou quando foram convidados 
para se tornarem membros do grupo de trabalho, eles descreveram que existiram um misto de incertezas por náo saberem com que tipo (fisicamente e psicologicamente) de crianças e adolescentes iriam lidar; em contrapartida, também se sentiram entusiasmados e interessados por uma proposta de trabalho táo desafiadora. Essa primeira categoria foi denominada de Contato Inicial. Os participantes $\mathrm{E}$ e $\mathrm{F}$ relatam que:

A reaçáo inicial de participaçáo no Projeto foi de descoberta e encantamento, até o início do Projeto não sabia como era a vivência com as doenças do sangue, algumas das doenças foram conhecidas ao longo das açóes realizadas no Hemocentro. (Participante E).

A minha intenção, desde o início, foi me integrar a um Projeto com objetivos recreativos, também pedagógicos, para crianças hospitalizadas. Sempre foi o campo que mais me interessou por motivos pessoais e por conseguir compreender a importância de pequenas atividades recreativas para elas. (Participante F).

Outra unanimidade nas respostas foi o fato de imaginarem que as atividades a serem desenvolvidas no Hemocentro não poderiam apresentar muitas exigências dos aspectos físicos dos pacientes, como correr e pular, devido às doenças do sangue. Os integrantes pensavam inicialmente que não haveria contato físico com os atendidos, uma vez que acreditavam que as pessoas estariam nas macas fazendo transfusão de sangue e o Projeto desenvolveria apenas atividades de contação de histórias e pintura. Vejamos o que relatam os participantes A e L:

Desde a primeira vez que pudemos ter o contato com as crianças e adolescentes dentro do Hemocentro minha percepçáo mudou, visto que, encontrei crianças e adolescentes por vezes dispostos, que estavam alegres, brincando na sala de espera, conversando e nem sempre estão em transfusão, sentados ou deitados em tratamento, e mesmo alguns com bolsa de sangue, eles conseguem se movimentar com os devidos cuidados, mas não necessariamente estão "presos" aos aparelhos. (Participante L).

A princípio minha visão era de que seriam pessoas com problemas relacionados ao sangue e que por meio de visitas ao Hemocentro realizavam procedimentos para assegurar um prolongamento de vida, até o início do Projeto o único caso de Hemofilia que eu tinha conhecimento era do sociólogo "Betinho", (Herbert José de Sousa),[...] Com a participação no Projeto posso afirmar que houve uma mudança significativa com relação a percepção que tenho para com as crianças e adolescentes e também os adultos (idosos) [...]E percebo que as pessoas que participam do Hemocentro são cidadáos de direito que convivem com uma diversidade funcional que requer apoio constante de equipes médicas, mas em especial das famílias, as crianças são alegres e participativas, como toda criança é. (Participante A).

Mediante os primeiros contatos com toda a equipe de profissionais e também com as crianças, adolescentes e seus familiares, foi possível perceber que, mesmo que o local das atividades (a sala de espera) náo permita o desenvolvimento de algumas atividades devido às limitaçóes do espaço físico e da dinâmica da instituição, mesmo assim, foi possível desenvolver diferentes atividades que exploram o ambiente disponível. Portanto, foram realizadas açóes que despertam nos membros do Projeto a criatividade e a imaginação, atividades que foram rigorosamente discutidas desde desenvolvimento e planejamento e 
que buscaram propiciar a todas as pessoas atendidas e seus familiares e ou responsáveis uma ressignificação das suas idas e permanências nas dependências do Hemocentro.

A segunda categoria de análise foi intitulada Modificaçáo de Conceitos. As concepçóes dos estudantes sobre as crianças, os adolescentes, suas patologias e potencialidades foram modificadas através das práticas e dos saberes envolvidos. Eles passaram a repensar os planejamentos, levando em consideraçáo as potencialidades e capacidades das pessoas que ali sempre se encontram, visando uma socialização entre todas os sujeitos envolvidos na dinâmica proposta pelo Projeto (pacientes, familiares, colaboradores - acadêmicos e professores - e a equipe de saúde). Em relação a essa temática, os participantes L e G afirmaram:

A atividade da "bolinha" sem dúvida é a mais legal, pois é uma forma diferente de conhecer um ao outro, pois sempre tem crianças e adolescente novos. Essa atividade nos ajuda a ter uma interação maior com os pacientes e acompanhantes, porque fazemos variaçóes que nos permite uma comunicação mais suave, quebrando aquele clima de hospital. O momento que mais me marcou foi em uma atividade realizada para as crianças conhecerem mais sobre o ECA - Estatuto da Criança e do Adolescente, que em determinado momento uma das crianças disse que não teria direito de dar opiniáo, e nos do Projeto pudemos intervir, fazendo-a refletir a respeito de sua fala. (Participante G)

Gosto das atividades de adivinhação e raciocínio, pois permite com que as crianças e adolescentes usem sua imaginação, e faz com que as conheçamos mais, por meio de seus saberes expressos em suas falas e ações. (Participante L).

Por meio das diferentes estratégias educacionais e lúdicas que o Projeto desenvolve, observou-se que as práticas educativas desenvolvidas no Hemocentro contribuem significativamente para o processo de formaçáo dos estudantes, visto que tem possibilitado refletir sobre o aprendizado discente, bem como sobre as futuras atuaçóes profissionais no campo da educação em diferentes contextos. No tocante à categoria Formaçáo, os participantes $\mathrm{G}$ e E enfatizam:

O Projeto contribui e muito para a minha formação, pois é um espaço que posso conhecer mais sobre a doença e a experiência de trabalhar com as limitaçóes que a doença lhes exige. Como futura professora de Educação Física é de suma importância passar por isso, pois nos faz repensar as nossas atitudes como educadora e como pessoa, visto que a cada encontro é um aprendizado novo, nós participantes somos os que mais aprendemos com os pequenos. (Participante G)

Não há como dimensionar a contribuição do Projeto, ele tem significância em todas as áreas de formação que posso pensar, seja pessoal, profissional e acadêmica, vejo o Projeto como um espaço de estudo e aprendizado ímpar, e sinto muita falta de atuar constantemente nas atividades do grupo. (Participante E)

É notório que cada participante teve um momento muito marcante no Projeto e eles descrevem que o trabalho extensionista contribui para a formaçáo profissional e humana de cada um. Todavia, em meio às diferentes respostas obtidas nas perguntas, verifica-se que as açóes que mais marcaram os participantes referem-se às práticas 
educativas realizadas no Dia Mundial do Hemofílico, evento que foi realizado em uma praça da cidade, no dia 17 de abril de 2016, para conscientização da sociedade sobre a Hemofilia e os cuidados necessários.

Outra atividade marcante foi o evento de encerramento das atividades do ano de 2015 cujo objetivo foi discutir e refletir a respeito do Estatuto da Criança e do Adolescentes - ECA (BRASIL, 1990) e a sua relação com o cotidiano das crianças, adolescentes e adultos com diferentes patologias. Esses foram momentos em que as famílias, os pacientes e os membros do grupo se mobilizaram em tardes de aprendizado e participação social.

Com base nisso, o Projeto tem permitido refletir a respeito das práticas educacionais e lúdicas e sua importância na formação dos educadores; o trabalho também faz repensar concepçôes sobre pessoas Hemofílicas, aquelas que têm Anemia Falciforme, Talassemia e o papel que exercem na sociedade. A cada prática educativa, são reafirmados novos olhares e práticas na formaçáo dos estudantes, que cada vez mais conseguem compreender o papel fundamental no exercício da profissão, no cuidado com as crianças e adolescentes, no respeito e conhecimento da diversidade e na luta coletiva pela garantia dos direitos dessas pessoas a um tratamento com dignidade, tanto no que se refere aos medicamentos, a garantia do sangue e sua qualidade nos Hemocentros quanto aos profissionais e atividades que proporcionem bem-estar, acolhimento e maior adesão ao tratamento.

\section{Consideraçóes finais}

A partir dessas experiências vivenciadas no Hemocentro, pode-se afirmar que o Projeto de Extensão tem contribuído significativamente para a formação humana e acadêmica dos seus participantes. A área de estudo sobre pessoas em tratamento de saúde em Hemocentros necessita de mais pesquisas, considerando a compreensão das interfaces do campo educacional associadas à saúde, em especial, a relação da Educação Social em Saúde.

A integraçáo dos participantes do Projeto e o conhecimento das pessoas atendidas têm possibilitado a construção de brincadeiras e açóes em espaços abertos e fechados. Os saberes dos diferentes cursos de graduaçáo, em especial de Pedagogia e Educaçáo Física, promovem ações multidisciplinares, as quais têm possibilitado a construção de fundamentos teóricos para atuaçáo lúdica e educativa com pacientes que frequentam Hemocentros, bem como de materiais didáticos e produçôes acadêmicas para outros Projetos de Extensão nessa mesma área.

É possível afirmar que, no decorrer das práticas educativas, o Projeto contribui para o desenvolvimento afetivo, cognitivo, social e pedagógico das pessoas em tratamento de saúde, tendo em vista que elas apresentam uma maior desenvoltura desde quando o Projeto teve início em 2015, não apenas com os integrantes do Projeto, mas também nas relaçôes estabelecidas com toda a equipe dos profissionais de saúde do Hemocentro.

O trabalho extensionista propicia bem-estar para todas as pessoas dentro da unidade de atendimento, sejam profissionais de saúde, pacientes, familiares e todos os participantes do Projeto, pois torna o ambiente mais caloroso, humanizado, pertencente, afetivo e, acima de tudo, alegre e vivo. Observa-se também uma maior adesão ao tratamento, pois as crianças e adolescentes solicitam que as consultas sejam marcadas nos dias de realização do Projeto. 
Como resultados, também é possível identificar que os membros do Projeto de Extensão têm dado um novo sentido às suas práticas e superaram as indagaçóes e impressóes iniciais sobre os pacientes. Os princípios teóricos da Educação Social contribuem para o trabalho com os pacientes para que eles compreendam a necessidade dos cuidados com a saúde e da luta pela garantia e manutenção dos seus direitos básicos. Outrossim, as açóes no Hemocentro possibilitam que os pacientes interajam entre si e construam soluçóes coletivas para seus problemas e também se divirtam com as atividades e brincadeiras desenvolvidas.

\section{Referências}

BARDIN, L. Análise de Conteúdo. Lisboa: Edições 70, LDA, 2009.

BRAGA, J. A. P. Medidas gerais no tratamento das doenças falciformes. Revista Brasileira de Hematologia e Hemoterapia, São José do Rio Preto, v. 29, n. 3, p. 233-238, jul./set. 2007. Disponível em: <http://www.scielo.br/pdf/rbhh/v29n3/v29n3a09.pdf>. Acesso em: 10 mai. 2016.

ABRASTA, Associação Brasileira de Talassemia. Definição Talassemia: A Talassemia não é contagiosa e não é causada por deficiência na dieta. São Paulo, 2016. Disponível em: <http://www.abrasta.org.br/definicao-talassemia >. Acesso em: 01 ago. 2016.

BRASIL. Lei n. 8.069, de 13 de julho de 1990. Dispõe sobre o Estatuto da Criança e do Adolescente e dá outras providências. Diário Oficial da União. Brasília, 13 jul. 1990. Disponível em: <http://www.planalto.gov.br/ccivil_03/leis/L8069.htm>. Acesso em: 10 ago. 2016.

FBH, Federação Brasileira de Hemofilia. 0 que é Hemofilia? Distúrbio genético e hereditário que afeta a coagulação do sangue. Barueri, 2016. Disponível em: <http://www. hemofiliabrasil.org.br/hemofilia/o-que-e/>. Acesso em: 18 fev. 2016.

GAZZINELLI, M. F et al. Educação em Saúde: conhecimentos, representações sociais e experiências com doenças. Cad. de Saúde Pública, Rio de Janeiro, v. 21, n. 1, p. 200-206, jan./fev. 2005. Disponível em: <http://www.scielo.br/pdf/csp/v21n1/22.pdf>. Acesso em: 20 fev. 2016.

INVERNIZZI, L.; VAZ, A. F. Tempo e conhecimento na educação física dos primeiros anos do ensino fundamental em classe hospitalar: algumas questões. Ágora: para la educación física y el deporte, Valladolid, n. 18(1), p. 49-60, jan./abr. 2016. Disponível em: <http:// agora-revista.blogs.uva.es/files/2016/05/agora_18_1d_invernizzi_et_fezvaz.pdf >. Acesso em: 10 ago. 2016.

LIEBERMAN, D. A. Interactive video games for health promotion: Effects on knowledge, selfefficacy, social support, and health. In: SREET, R. L.; GOLD, W. R.; MANNING, T. (orgs.) Health promotion and interactive Technology: Theoretical applications and future directions. Mahwah: Lawerence Erlbaum Associates, 1997, p. 103-120. 
MÜLLER, V. R. et al. A formação do profissional da Educação Social: espectros da realidade. In: XVIII Seminário Internacional de Formação de Professores para o MERCOSUL/CONE SUL, 18, 2010, Florianópolis. Anais eletrônicos... Florianópolis: UFSC, 2010. p. 446-456. Disponível em: <http://seminarioformprof.ufsc. br/files/2010/12/M\%C3\%9CLLER-Ver\%C3\%B4nica-Regina3.pdf>. Acesso em 5 jul. 2016.

NATALI, P. M. Formação profissional na Educação Social: Subsídios a partir de experiências de educadores sociais latino americanos. 2016, Tese (Doutorado em Educação), Universidade Estadual de Maringá, Maringá, 2016.

OLIVEIRA, L. S. Brincar (es) na infância: possibilidades no contexto da doença falciforme e da Hemofilia. (Dissertação de Mestrado) Juiz de Fora: Universidade Federal de Juiz de Fora, 2010.

PAULA, E. M. A. T.; FOLTRAN, E. P. Brinquedoteca hospitalar: direito das crianças e adolescentes hospitalizados. Revista. Conexão, Ponta Grossa, 2007, v. 3, n. 1, p. 22-25, 2007. Disponível em: <http:// www.revistas2.uepg.br/index.php/conexao/article/view/3828/2707>. Acesso em: 10 mai. 2016.

SOUZA, C. R. T. Educação Social e Avaliação: Indicadores para contextos educativos diversos. 2016, Tese (Doutorado em Educação), Universidade Estadual de Maringá, Maringá, 2016.

VYGOTSKY, L. S. O papel do brinquedo no desenvolvimento. In: VYGOTSKY, L. S. A formação social da mente. São Paulo: Ed. Martins Fontes, 1991. p. 61-69. 